\title{
STUDY OF KNOWLEDGE LEVEL OF FARMERS FOR MOST IMPORTANT INSECT PESTS WHICH INFEST OLIVE TREES IN AL-BALQA' GOVERNORATE IN JORDAN
}

(Received: 13.7. 2008)

\author{
By \\ A. N. Al-Shadiadeh \\ Department of Plant Production \& Protection, Faculty of Agricultural Technology, AL-Balqa' Applied \\ University, Al-Salt (19117), Jordan
}

\begin{abstract}
Olive tree is considered one of the important crops in Jordan for local consumption and export. Olive tree can grow in different locations starting from Ghur and upland. Decreases of olive productivity in different growing seasons in these areas were mainly due to the lack of knowledge cultivation requirements and also due to the absence of the role of agricultural extension.

The aim of this study was to determine the knowledge levels of olive farmers about olive insects in the Al-Balqa' Governorate/Jordan and to study the relationship between the knowledge levels and some independent variables such as personal and professional characters of farmers. A sample of 236 farmers was selected and interviewed individually. Using a questionnaire included two parts; the first was the personal information of the farmers and the second was a measure of knowledge levels on the olive insects area.

Frequencies, percentages, mean standard deviations, Pearson and Spearman correlation, coefficient chi-square and t-test were used to test the hypothesis and to determine the relationship between dependent and independent variables.

\section{The most important results were:}

1- There was three categories for knowledge levels; low $(<16)$ degrees, medium $(16-26)$ degrees and high

(> 26) degrees. It was found that $16.9 \%, 65.7$, and $17.4 \%$ of the farmers fall in the low, medium, and high levels, respectively.

2- There was a significant relationship between knowledge level and each of educational level, devotion to agribusiness, and information resources.

3- There was no significant relationship between knowledge level and each of farmer age, number of family members, type of land holding, size of landholding and number of experience years.

Finally, the results of the study recommended that agricultural extension must take awareness of extra role for education and awareness of olive farmers and the dissemination of agricultural technology to them through a scientific and practical plan that includes simplifying the results according to the knowledge levels of farmers in this study area.
\end{abstract}

Key words: agricultural extension, insect pests, Jordan, knowledge level, olive farmers.
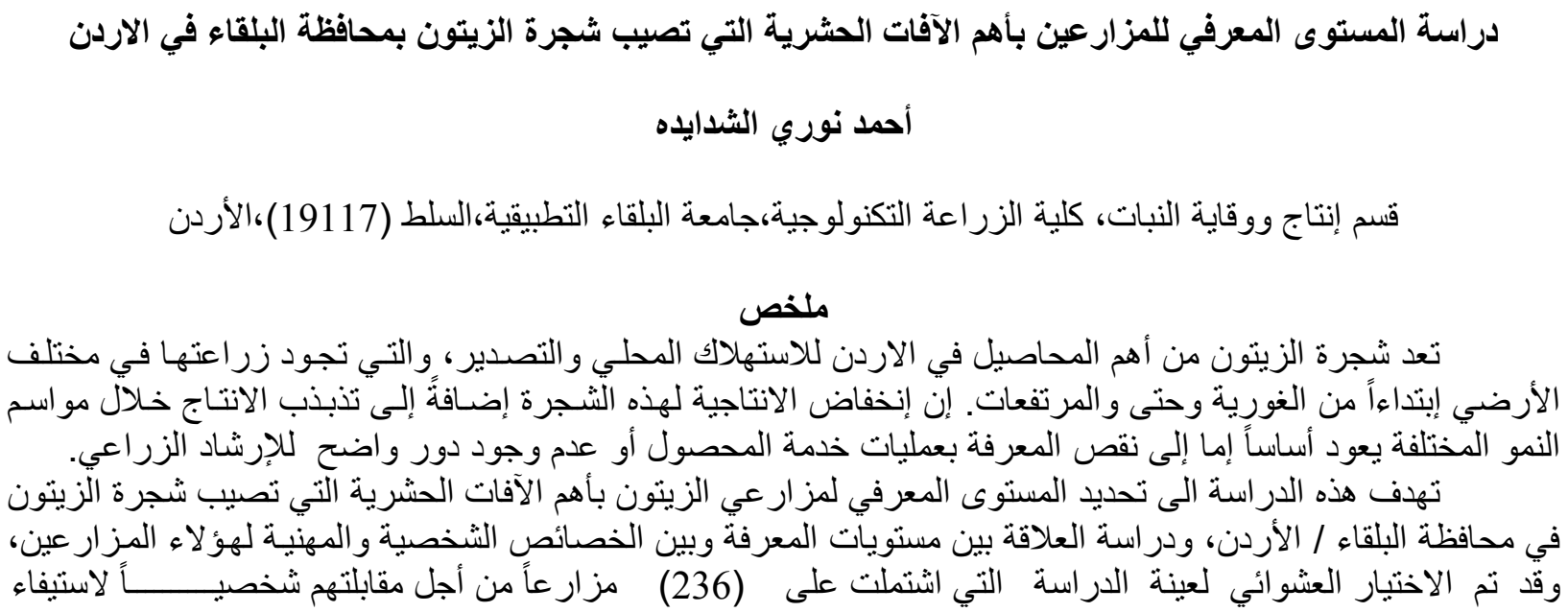


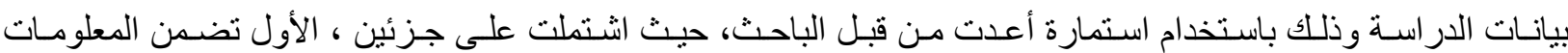

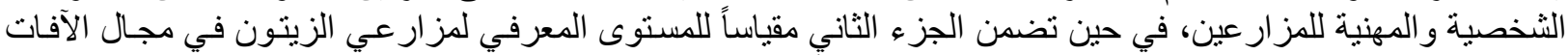

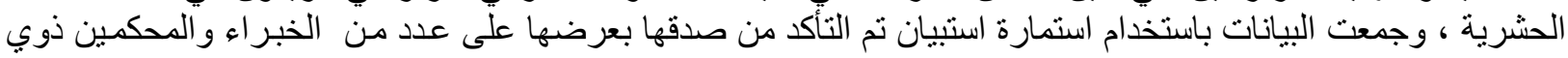

العلاقة

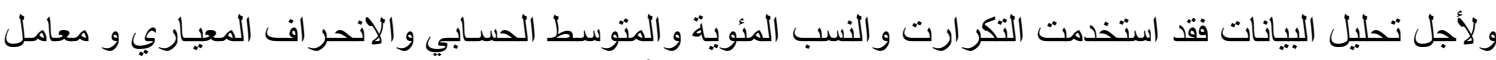

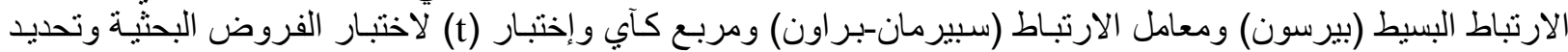

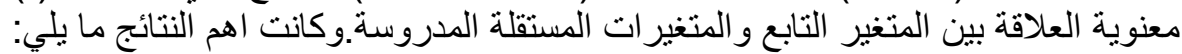

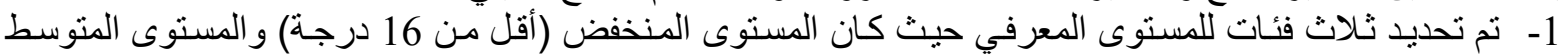

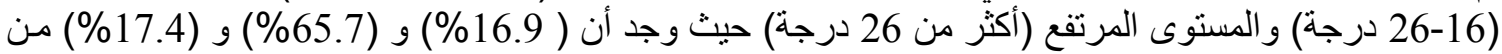
المبحوثين يقعون في الفئات أعلاه على العنى التو الي.

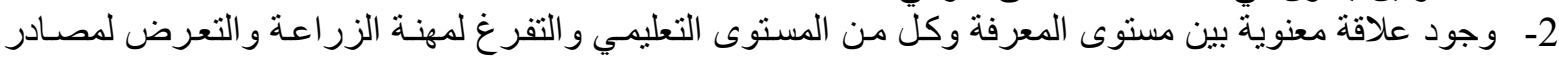
المعلومات. 3- لا نوجد علاقة معنوية بين المستوى المعرفي وكل من العمر و عدد أفر اد الأسرة ونوع الحيازة وحجم الحيازة وعدد

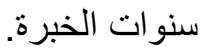

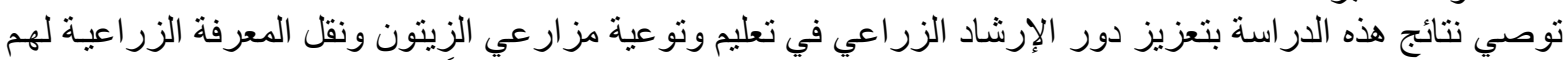

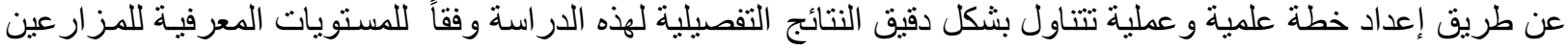
في منطقة الدر اسة.

ويعتمد تقدير المستويات المعرفيـة على تحديد القصور

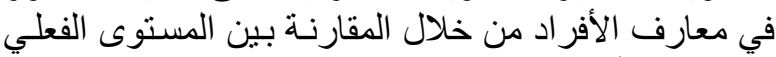

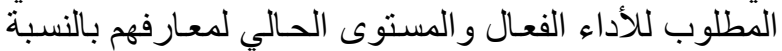

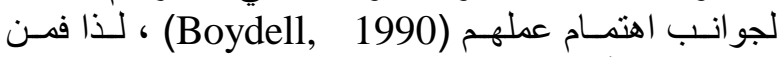

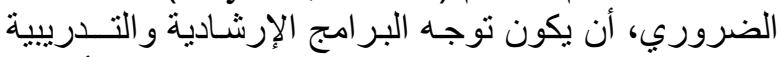

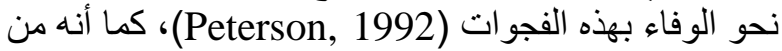

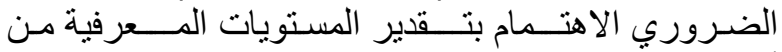

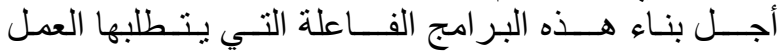

الزراعي (Radhakrishna \& Martin, 1999). تعتبر الآفات الحشرية من أهم المشـاكل الزراعية اعية التي

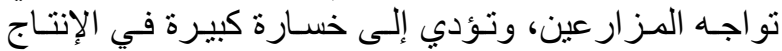

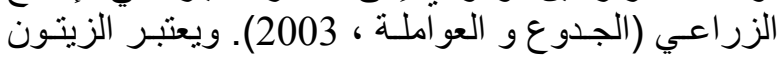

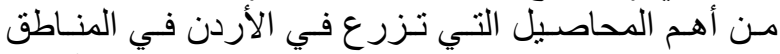

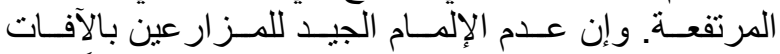

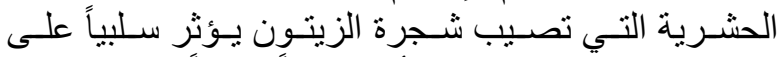

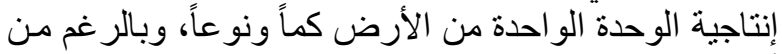

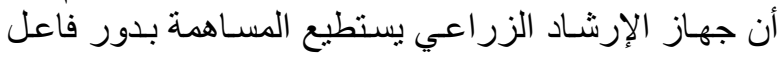

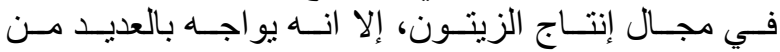

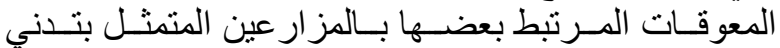

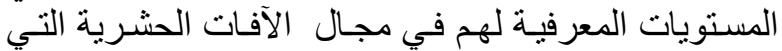

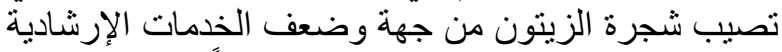

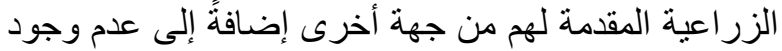

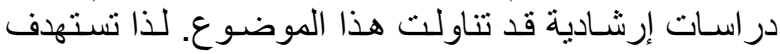

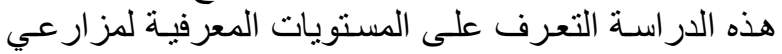

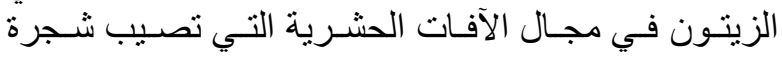

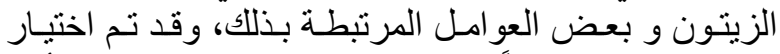

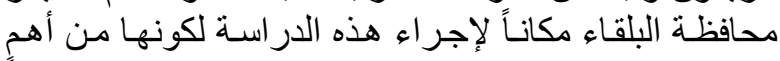

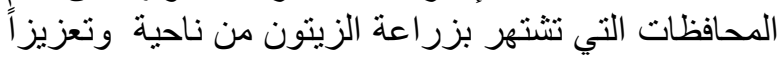

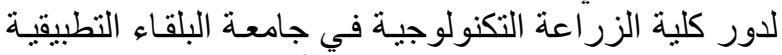
في خدمة المجتمع المحلي من ناحية أخرى.

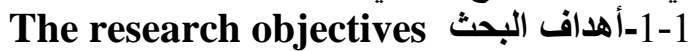

\section{1-مقدمة ومشكلة البحث}

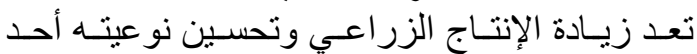

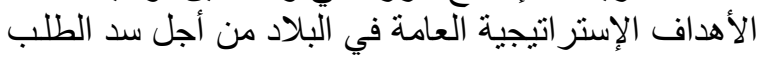

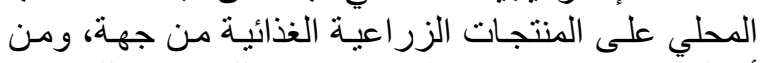

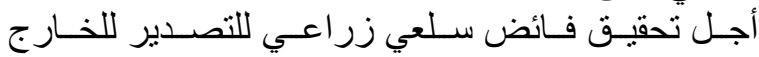

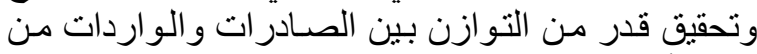

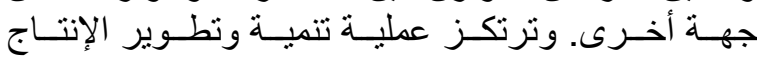
الزر اعي وزيادتـه على ثنلاث حلقات (الر افعي، 1991)

1- مستحدثوا التكنولوجيا الزر اعية مثنل مر اكز ومؤسسـات

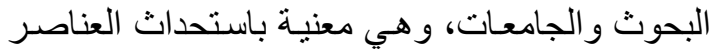

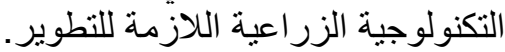

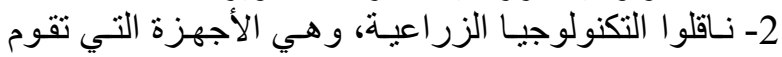

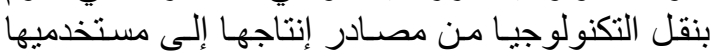

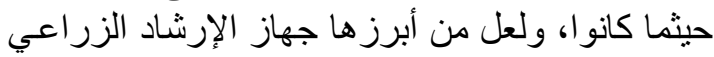

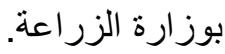

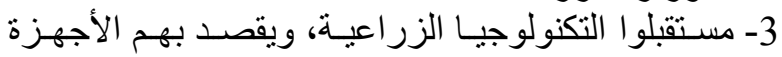

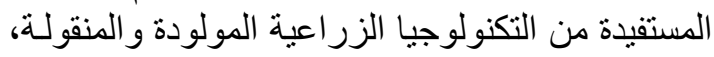

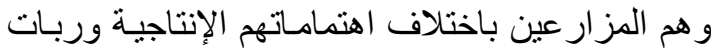
الأسر الريفية والثباب الريفي.

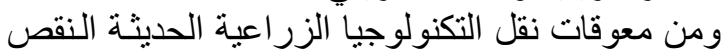

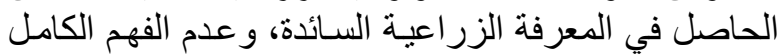

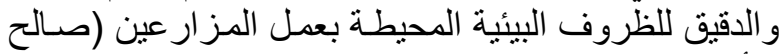

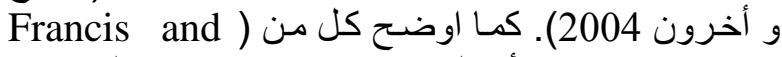

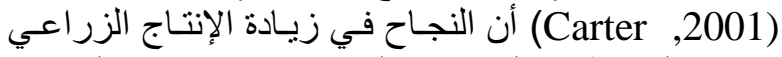

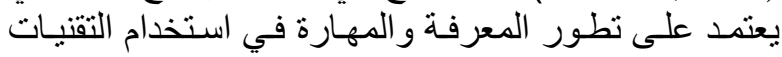

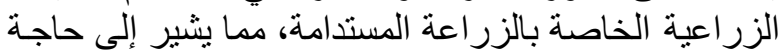

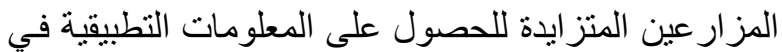

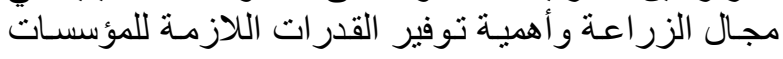

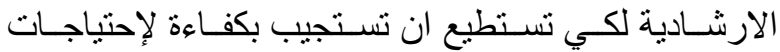

المـزارعين. (Fridgen, 1995)، و الارية (Battel and)

Kruger, 2005). 


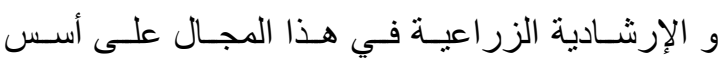

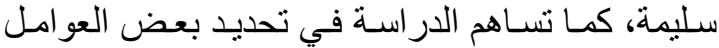

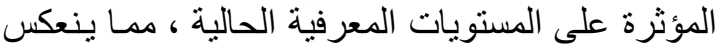
ايجابياً على إنتاجية محصول الزيتو الزيتون كماً ونوعاً.

The research method 1

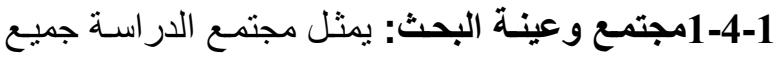

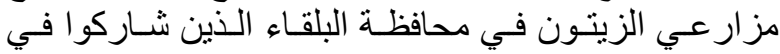

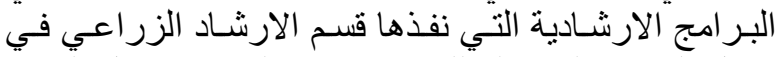

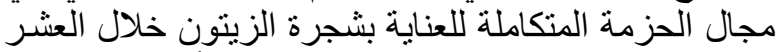

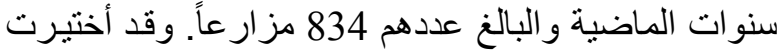

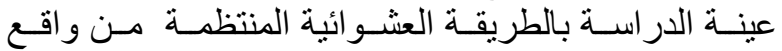

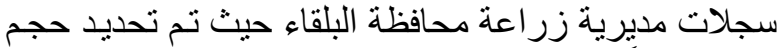
العينة طبقاً لمعادلة (Kreijcie \& Morgan , 1970)

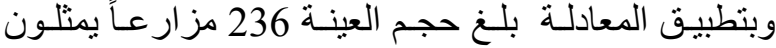

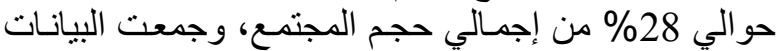

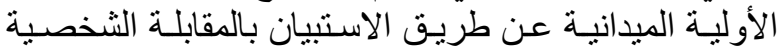

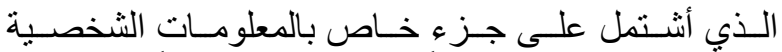

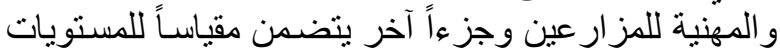

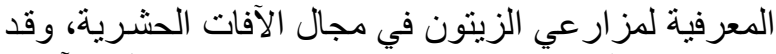
تضمن هذا المقياس (38) فقرة اختبارية في مجال الزئ الآفات

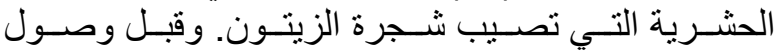

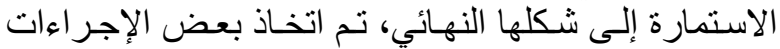
عليها وفي مقدمتها صدقها الظـاهري ( Face Validity )

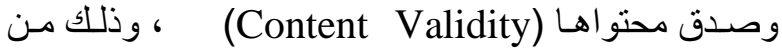

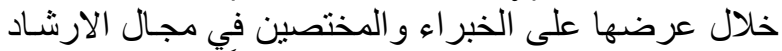

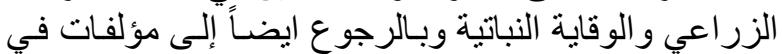

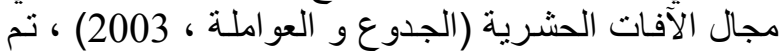

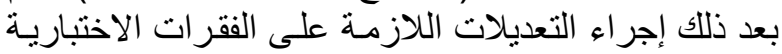

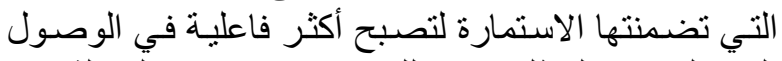

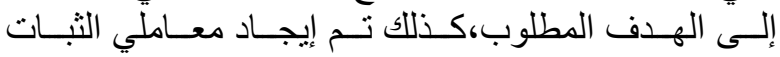

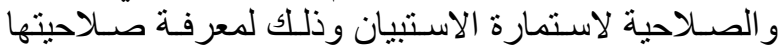
لقياس الظاهرة المر اد در استها ، وذللك عند إعادة استخدامها

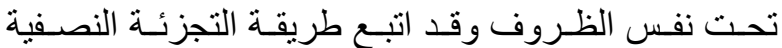

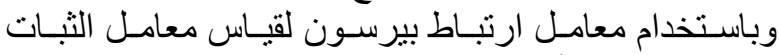

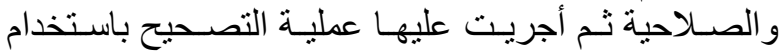
معادلـة سبيرمان بـر اون وكانت النتائج كمـا هـي بالجدول

\begin{tabular}{|c|c|c|c|}
\hline \multicolumn{4}{|c|}{ جدول (1) معامل الثبات والصلاحية للمقاييس المستخدمة } \\
\hline الصلاحية معلية & الثبات & نوع المقياس & P \\
\hline 0.97 & 0.90 & مستوى المعلومات الحالى & 1 \\
\hline 0.94 & 0.88 & التعرض لمصادر المعلومات & 2 \\
\hline
\end{tabular}

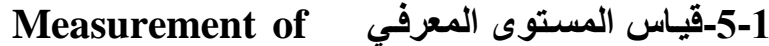

the level of knowledge

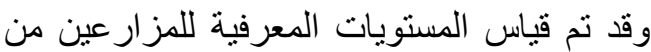

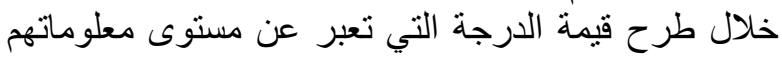

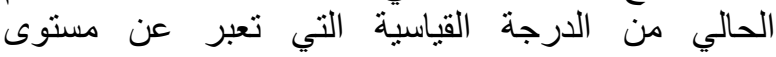
المعلومات المرغوب، حيث تم قياس المستويات المعرفية
يستهف البحث بصفة رئيسة تحديد المستوى المعرفي

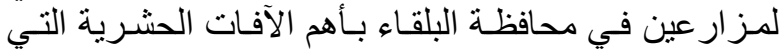

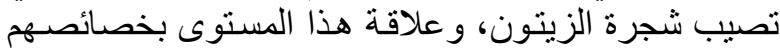
الثخصية والمهنية. وتتحصر الأهداف الفرعية لهية للار اسة في الآتي: - الكئ

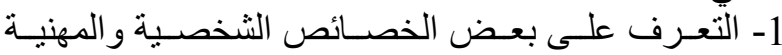

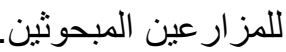

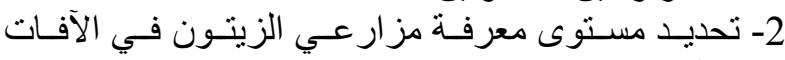

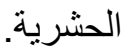

3- در اسة العلاقة بين مستوى معرفة مز ارعي الزيتون في

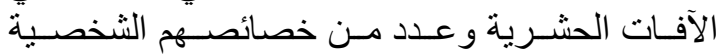

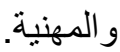

Used expressions-2-1 التعاريف الإجرائية

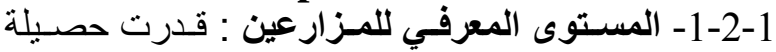

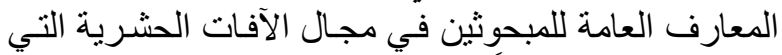

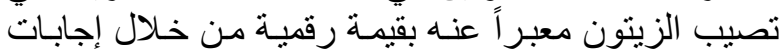

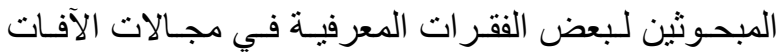

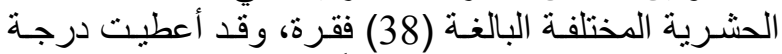

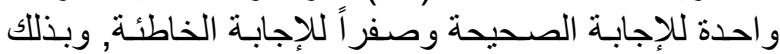

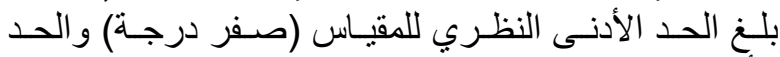
الأقصى النظري له (38 درجة الأنس).

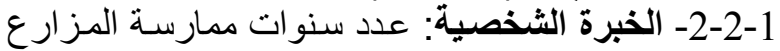

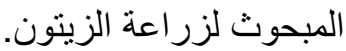

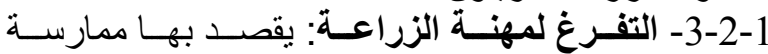

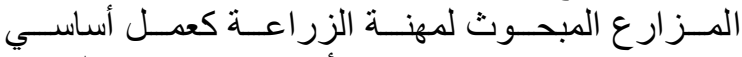

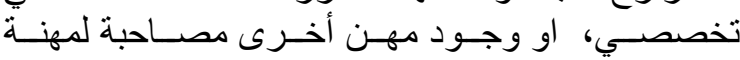

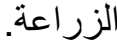

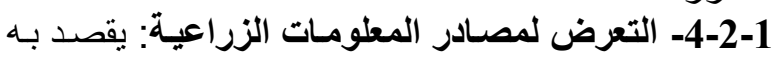

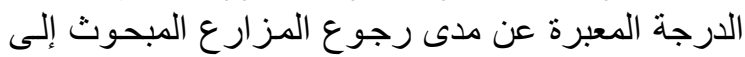

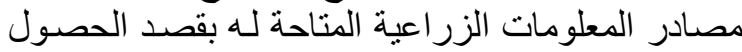

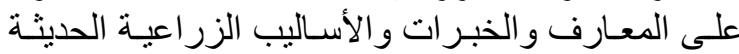

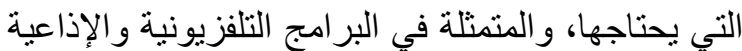

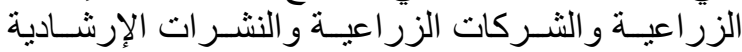

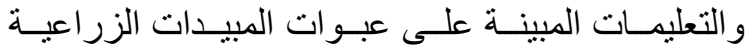

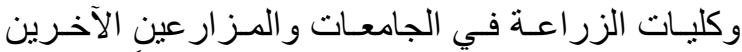

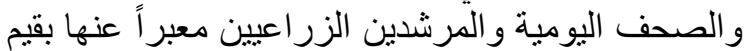

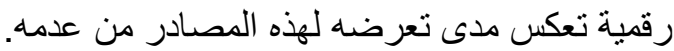

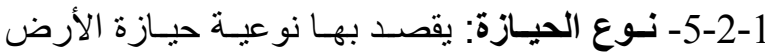

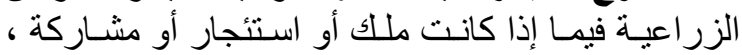
وما يتبع ذلك من حقوق التصرف بلت بها.

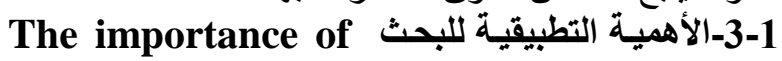
applied research تنبع الأهمية التطبيقية لهذه الدراسـة من أهميـة تحديد

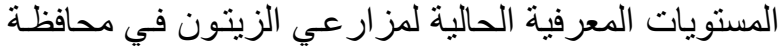
البلقاء ، و العوامل المؤثرة عليها مما يتيح الفرصة الفئة للعاملين

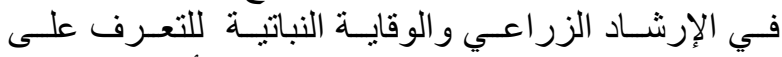

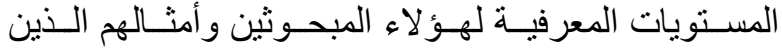

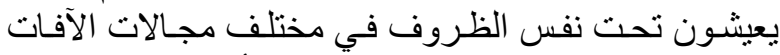
الحشرية. ويساهم هذا بدوره في وضع الأنشطة التنريبية 
1-2- المستويات المعرفية في مجال الآفات الحشرية التي تصيب شجرة الزيتون

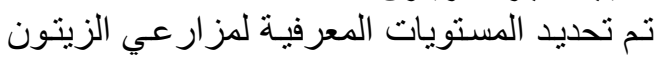

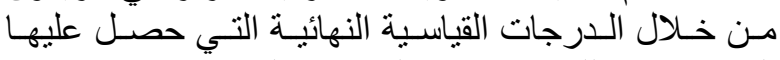
المبحوثون وذللك بطرح قيم الدرجات التي تعبر عن مستوى التئي

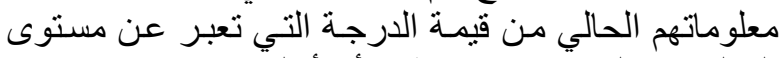

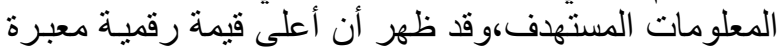

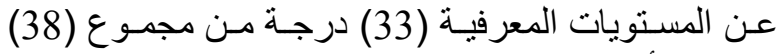

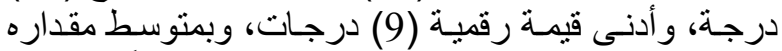

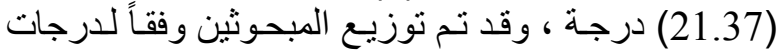

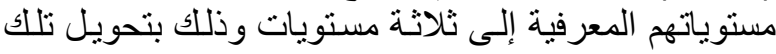

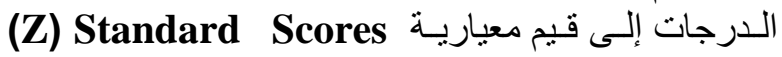
و هي على النحو الاتي : الثيات 1. ألمستويات المعرفية المنخفضة وقيمتها المعيارية اقل من

2. المستويات المعرفية المتوسطة وقيمتها المعيارية تتراوح

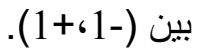

3. المستويات المعرفية المرتفعة وقيمتها المعيارية اكثر من المن

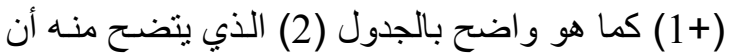

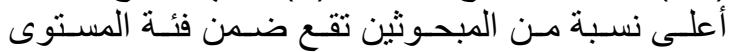

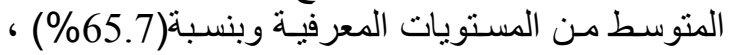

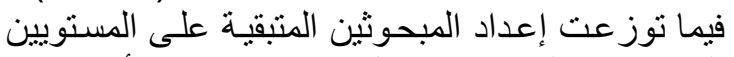

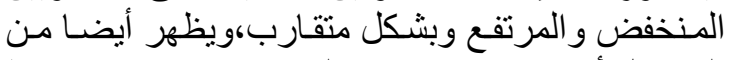

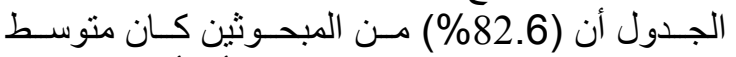

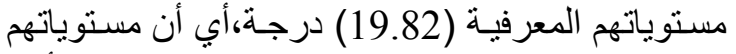

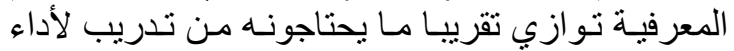

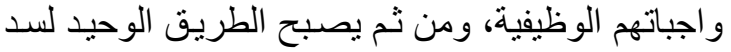

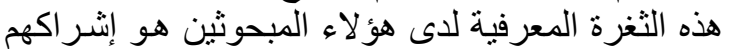
في دور ات تدريية وفقا للمحاور التي تناولتهاء لتها الدراسة.

\begin{tabular}{|c|c|c|c|}
\hline 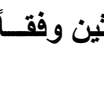 & & \multicolumn{2}{|c|}{ لكستوياتهم المعرفية. } \\
\hline المئوية & العدد & القيمة المعيارية & المعرفية \\
\hline 16.9 & 40 & اقل من (-1) & منخفض \\
\hline 65.7 & 155 & بين (-1+1) & متوسط \\
\hline 17.4 & 41 & اكثر من (+1) & مرتفع \\
\hline
\end{tabular}

S.d = 5.04، $\quad$ Mean $=21.37 ، \quad N=236$

2-2-العلاقة بين المستويات المعرفية والمتغيرات المستقلة المشمولة بالدراسة الماتوبات

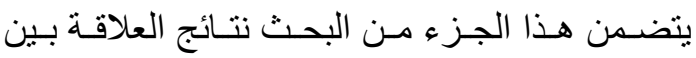

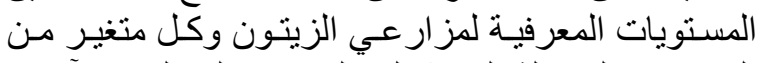

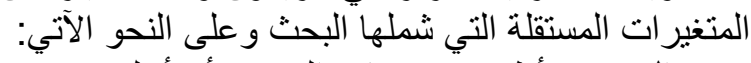

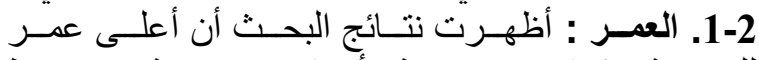

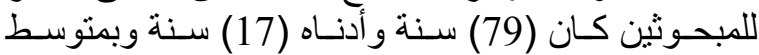

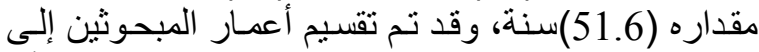

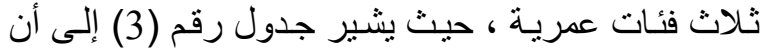

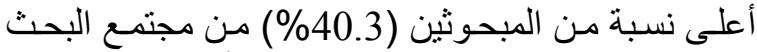
تقع ضدن الفئة العمرية (46-61) سنة و أدناها (8.1\%)

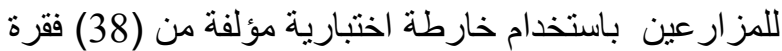

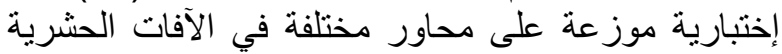

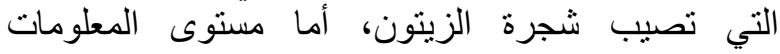

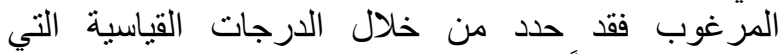
خصصت مسبقاً لكل فقرة من الفقرات، و اعتمدت الدرجة

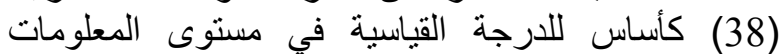

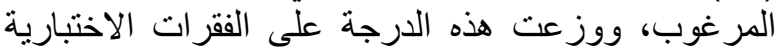
بو اقع درجة واحدة لكل فقرة حيث اعتمدت في ذلات اللك آراء

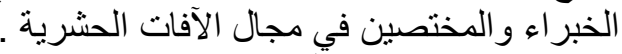

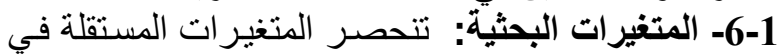

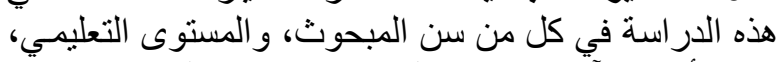

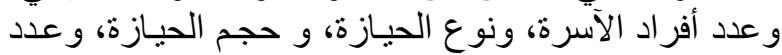

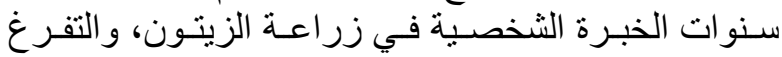

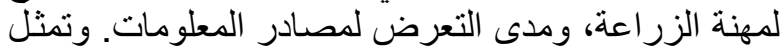
المتغير التابع في المستوى المعرفي للمبحوثين فئني في مجال ونئل

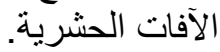

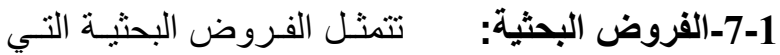

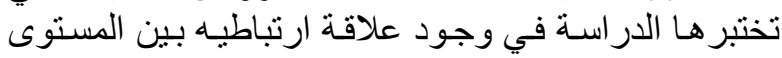

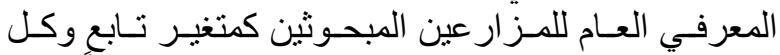

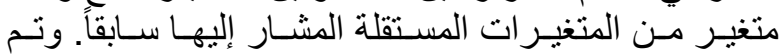

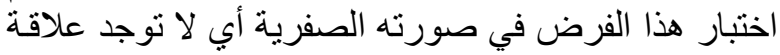

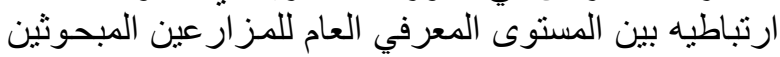

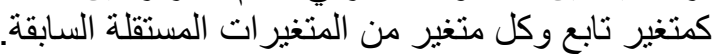

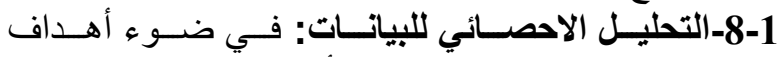

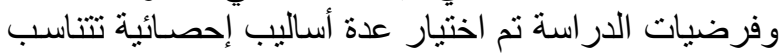

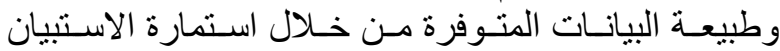

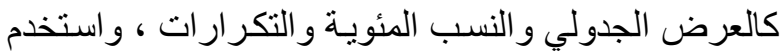

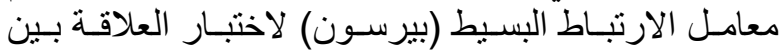

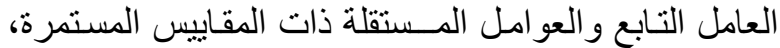

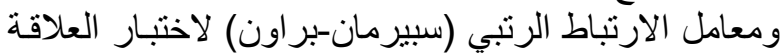

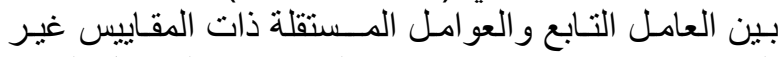

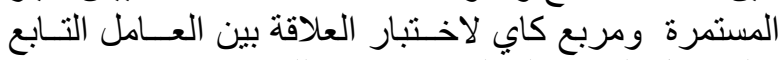

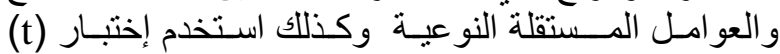

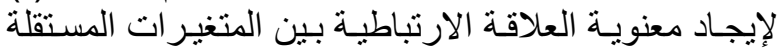

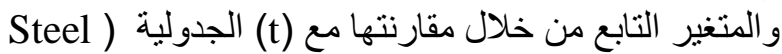

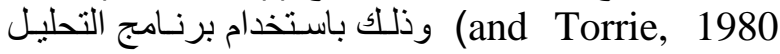
الإحصائي للعلوم الاجتماعية (SPSS).

\section{2- 2- النتائج ومناقشتها}

المستويات المعرفية لمزارعي الزيتون وعلاقتها ببعض ومناتئه

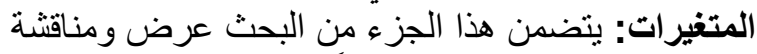

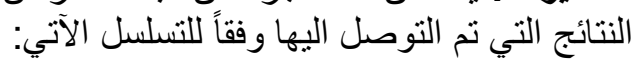

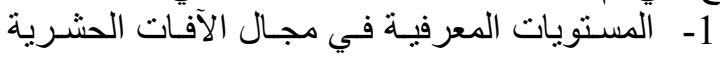

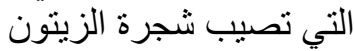

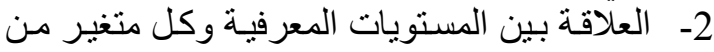

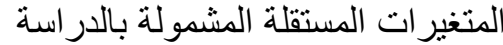

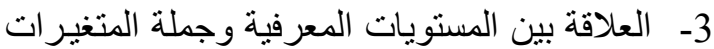
المستقلة المشمولة بالدر اسة. 


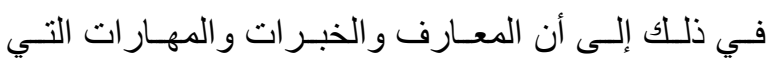

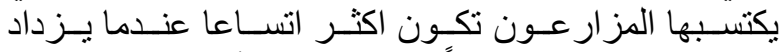

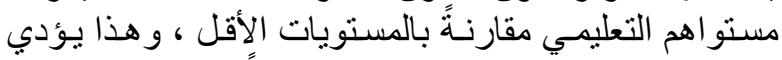

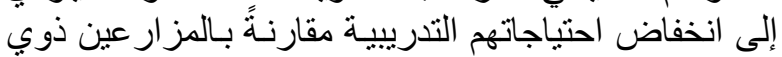

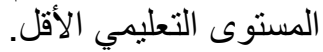

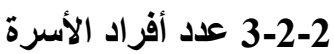

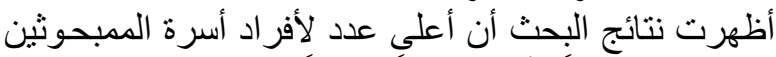

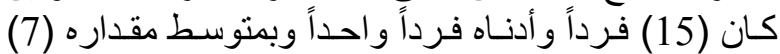

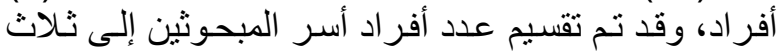

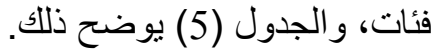

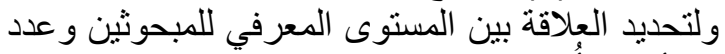

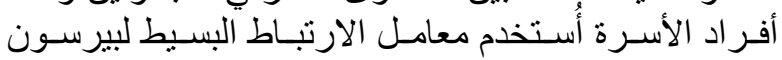

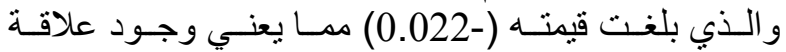
إرتباطية عكسية بين المتغيرين، ولتحديد التحيد معنوية هذه العلاقة

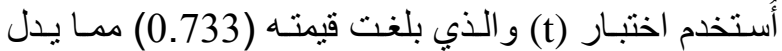

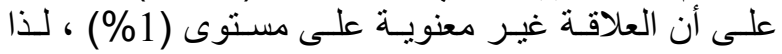

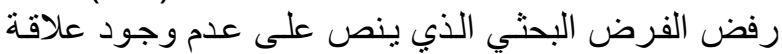

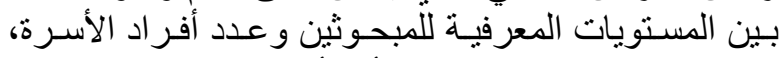

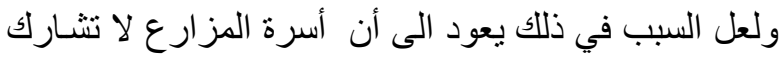

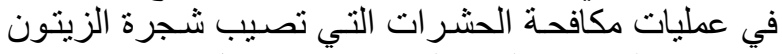

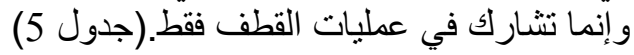

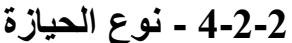

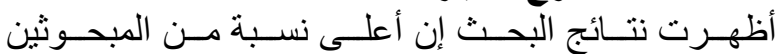

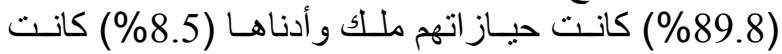

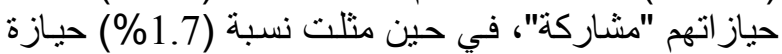

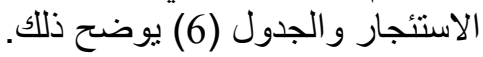

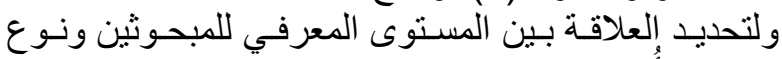

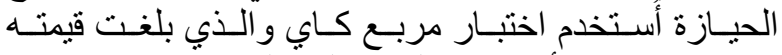

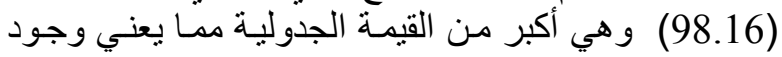

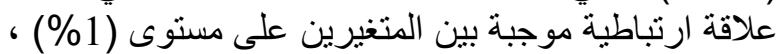

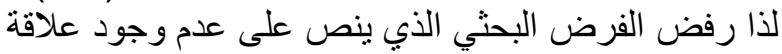

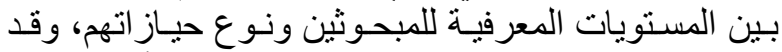

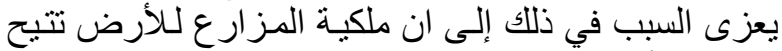

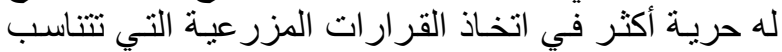
وظروفه الخاصة ومن ثم إرتفاع مستوى معرفته.

5-2-2

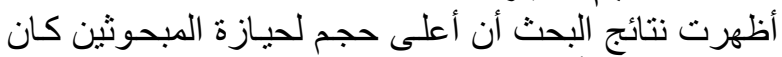

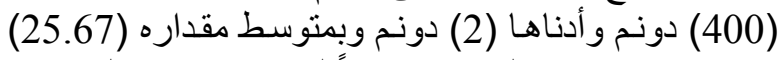

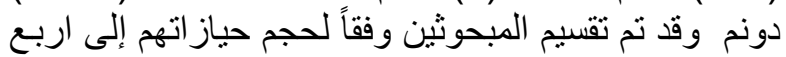

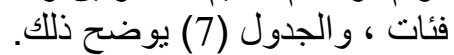

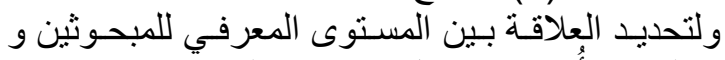

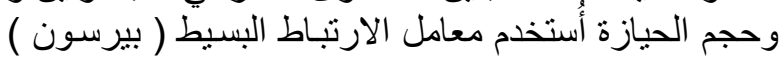

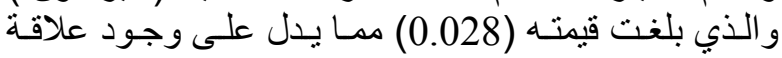

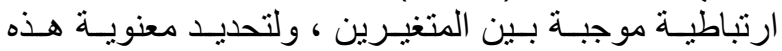

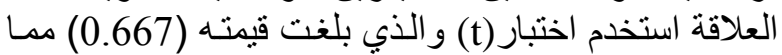

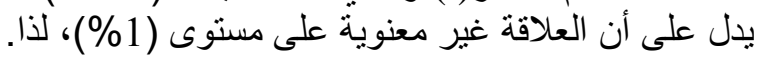

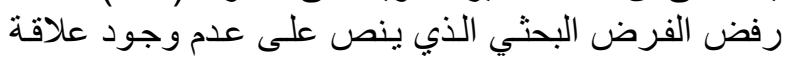

ضمن الفئة العمريـة (أقل من 30) سنة ، في حين مثلت

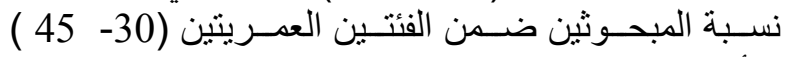

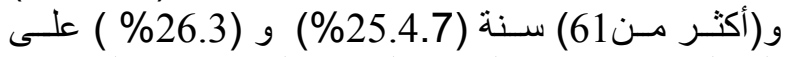

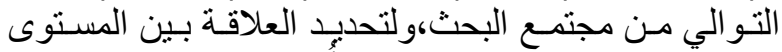

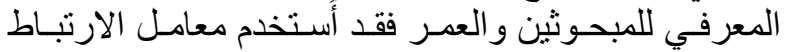

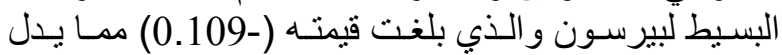

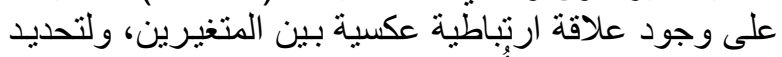

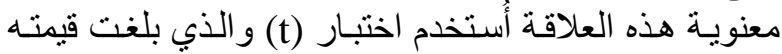

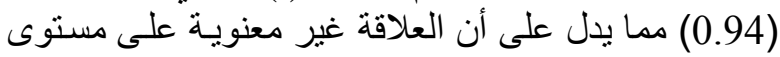

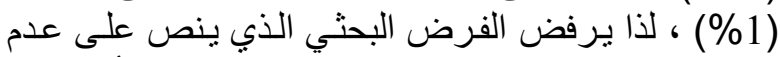

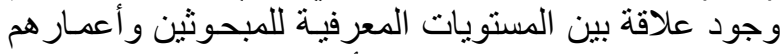
، وقد يعزى السبب في ذللك إلى أن المبحوثين يفقدون الكثير الكير الكير

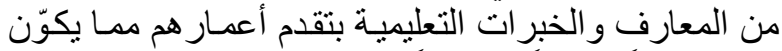

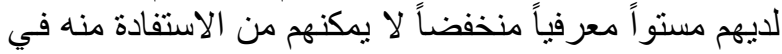
مجال عملهم ومن ثم يزيد من احتياجاتهم إلى التدريب.

جدول (3) الأعداد والنسبـب المئويـة للمبحوثين وفقتاً للعمـر وعلاقتـه. بمستوياتهم المعرفية العبد

\begin{tabular}{|c|c|c|c|c|c|}
\hline المعنوية & المحسوبة & الارتباط & المئوية & العدد & (العمريةت \\
\hline \multirow{4}{*}{ معنوية } & \multirow{4}{*}{0.94} & \multirow{4}{*}{$\begin{array}{c}- \\
0.109\end{array}$} & 8.1 & 19 & أقلّل من 30 \\
\hline & & & 25.4 & 60 & $45-30$ \\
\hline & & & 40.3 & 95 & $61-46$ \\
\hline & & & 26.3 & 62 & أكثر من 61 \\
\hline
\end{tabular}

2-2-2-2-المستوى التعليمي: أظهرت نتائج البحث إن أعلى

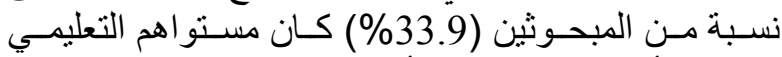

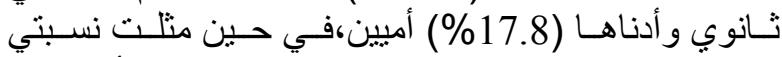

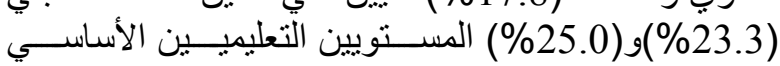

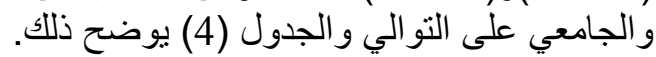

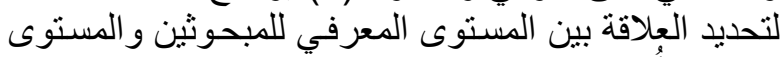

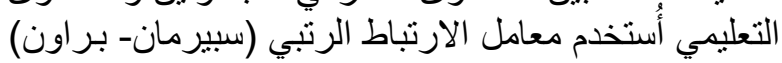

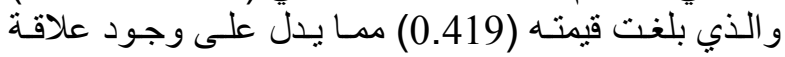

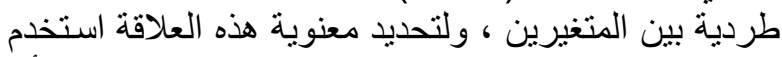

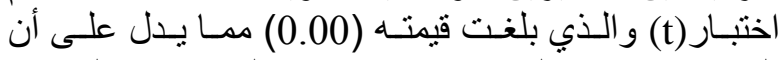

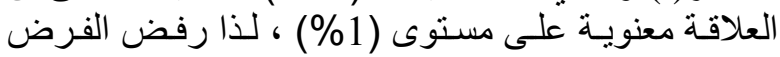

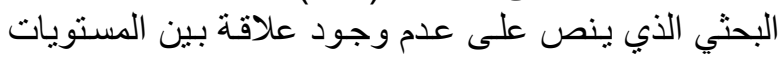

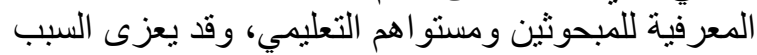

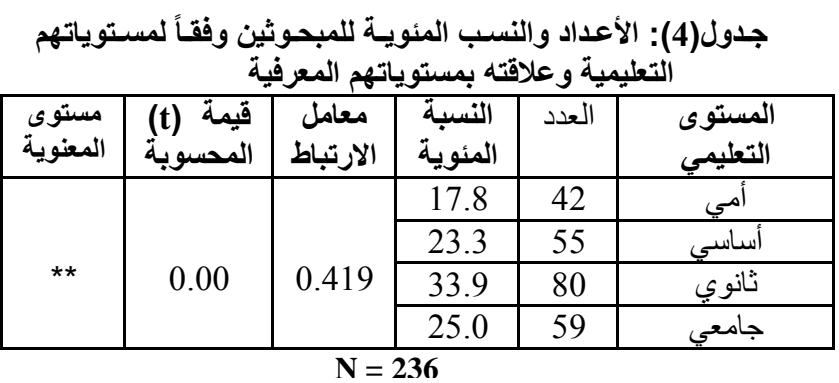



5داول 5-وحت 


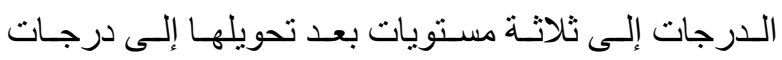

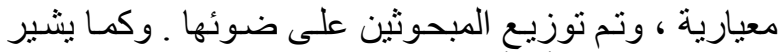

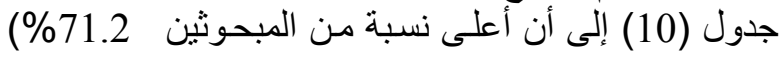

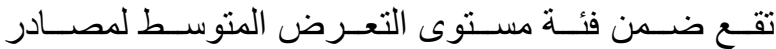

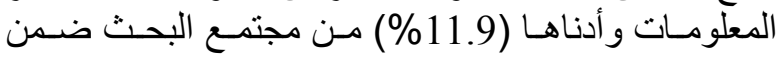

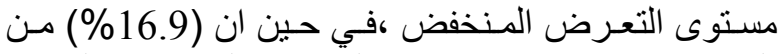

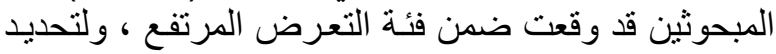

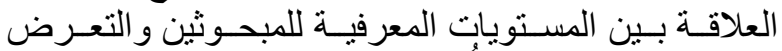

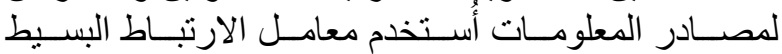

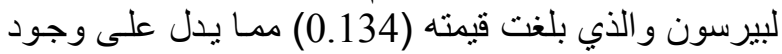

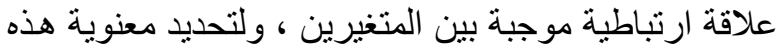

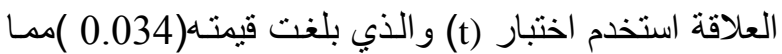

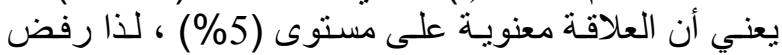

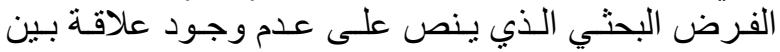

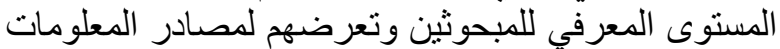

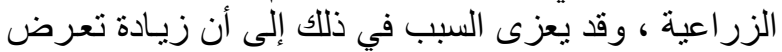
المبحوثين لمصادر المعلومات الزية الزئ اعية يقلل من إحتياجاتهم

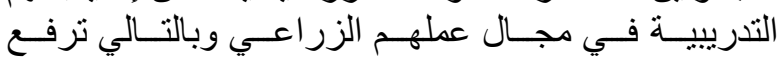
مستوياتهم المعرفية.

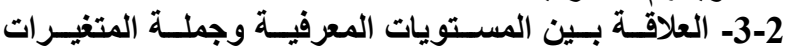

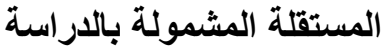

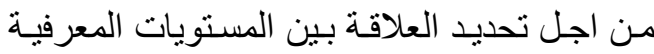

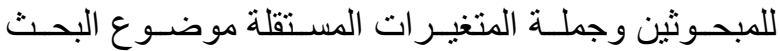

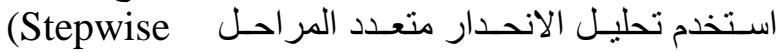
regression analysis)

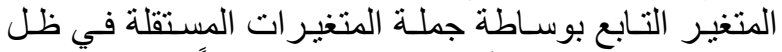

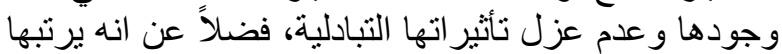

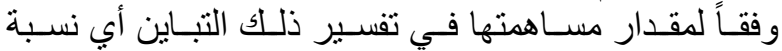
مساهتها في شرح التباين في مستوى المستويات المعرفيـة و الجدول الآتي يوضح ذلتك:
بين المستويات المعرفيـة للمبحوثين وحجم حياز اتهم، وقد

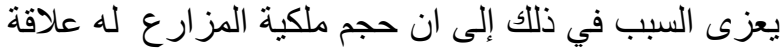

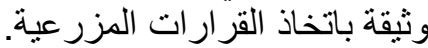
6-2-2 عدد سنوات الخبرة

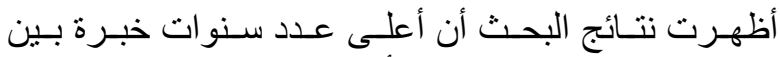

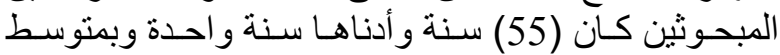
مقداره (19.44) سنة، وقد تم تقديم المبحوثين إلى ثناثلاث

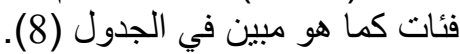

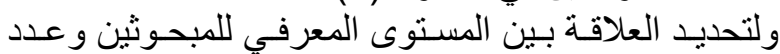

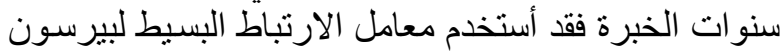

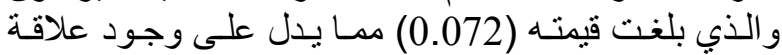
إرتباطية عكسية بين المتغيرين، ولتحديد مئيد معنوية هذه العلاقة

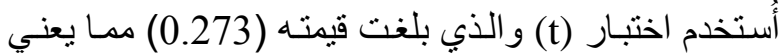

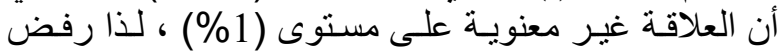

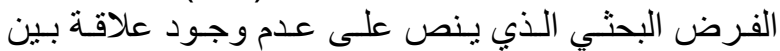

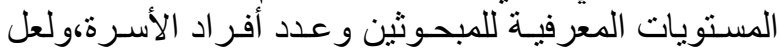

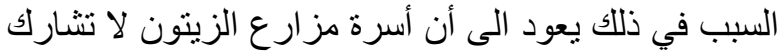

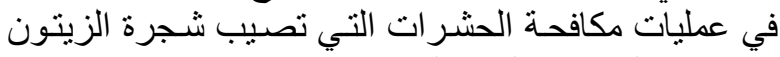

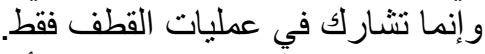

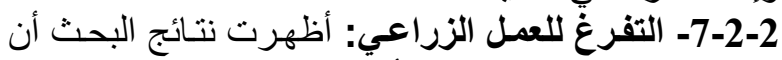

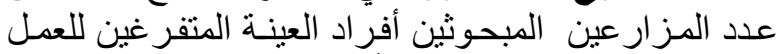

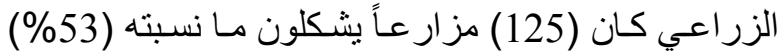

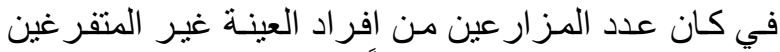

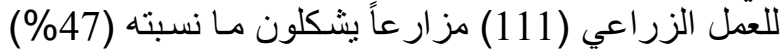

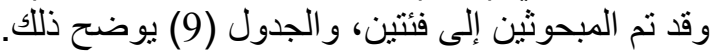

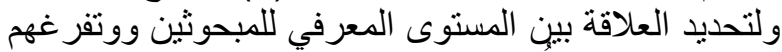

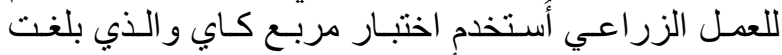

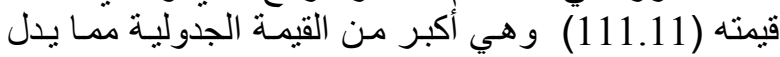

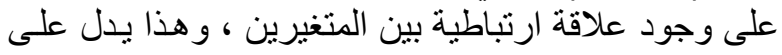

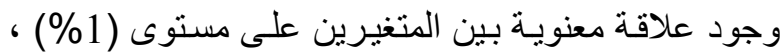

جدول (11) تحليل الاتحدار متعدد المراحل للمستويات المعرفية للمبحوثين وعلاقته بجملة متغيرات العوامل المستقلة

\begin{tabular}{|c|c|c|c|c|c|c|c|}
\hline Fنوية F & معامل الانحدار & معامل التئير فيد & $\begin{array}{c}\text { التحديد) معامل) } \\
\left(\mathbf{R}^{2}\right.\end{array}$ & 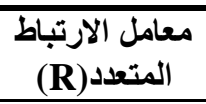 & الارتباط معامل & المتغيرات المستقلة & المراحل \\
\hline ** & 0.170 & 0.173 & 0.173 & 0.416 & 0.419 & المستوى التعليمي & 1 \\
\hline ** & 0.195 & 0.028 & 0.202 & 0.449 & 0.072 & عدد سنو ات الخبرة & 2 \\
\hline ** & 0.207 & 0.015 & 0.217 & 0.466 & $0.022-$ & عدد أفراد الأسرة & 3 \\
\hline
\end{tabular}

** معنوية على مستوى (1)

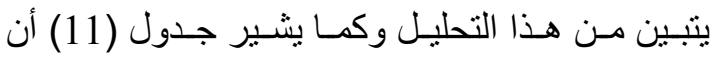

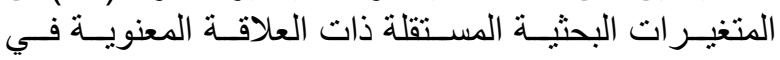

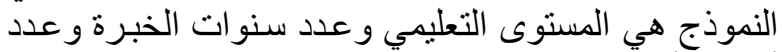

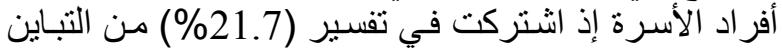

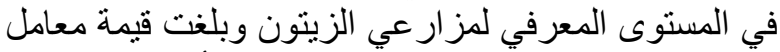

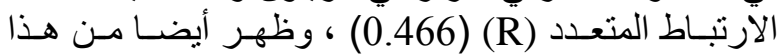

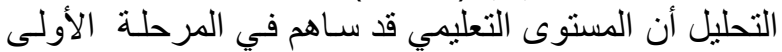

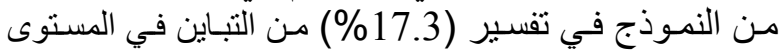

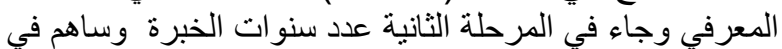

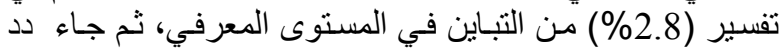

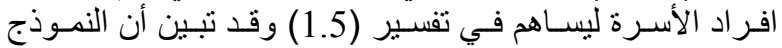

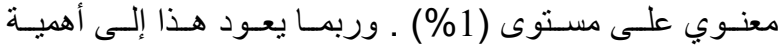

لذا رفض الفرض البحثي الذي ينص على عدم وجود علاقة

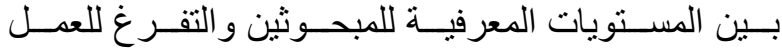

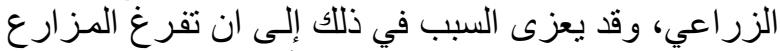

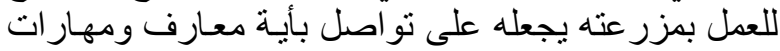
ت ت التعلق بشجرة الزينون.

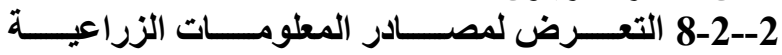

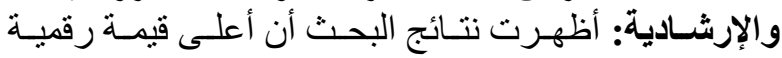

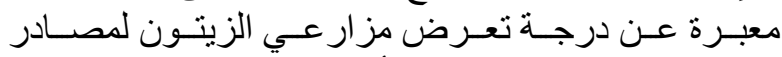

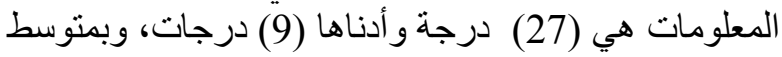

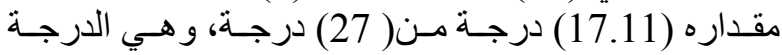

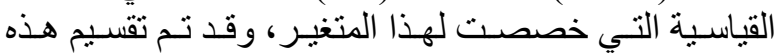




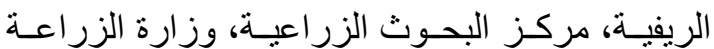

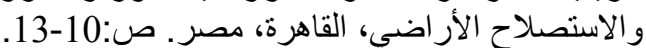

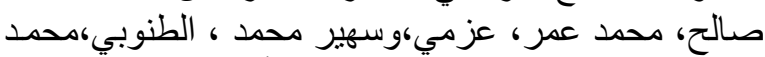

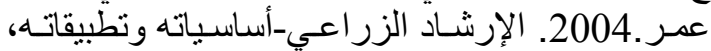

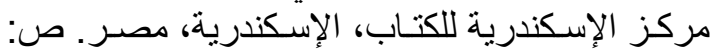

.315-314

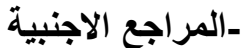

Battel R. D. and Krueger D. E. (2005). Barriers to Change: Farmers' willingness to adopt sustainable manure management practices. Journal of Extension, 43 (4).Available on line:http;//www.joe. org/joe/2005 august/a 7.html.

Boydell T.H. (1990). A Guide to the Identification of Training Needs. British Association for Commercial and Industrial Education, Second Edition, UK.

Fridgen, C. (1995), A National Strategic Plan for Natural Resources and Environmental Management Education. Journal of Extension, 33 (1). Available online: http://www.joe.org/joe/1995

February/a2.html

Francis C. A. and Carter H.C. (2001). Participatory education for sustainable agriculture: Every one a teacher, every one a learner. Journal of Sustainable Agriculture, 18(1), 71-83.

Krejcie Robert V. and Morgan Daryle W. (1970). Determining Sample Size for Research Activities, Educational and Psychological Measurement, College Station, Durham, North Carolina, U.S.A., Vol.,(30),607-610. Eterson R. (1992). Training Needs Analysis in the Workplace. Institute of Training and Development, Kogan, UK, 16pp.

Peterson R., (1992).Training needs analysis in the workplace .Institute of Training \& Development, Kogan, UK. P: 16.

Radhakrishna R. and Martin M. (1999). Program evaluation and accountability training needs of agricultural extension agents. Journal of Extension, 37 (3).

Steel R. and Torrie J. (1980). Principles and Procedures of Statistics. $2^{\text {nd }}$ edition. McGrawHill Book Company, Inc., NY, USA,485pp
المستوى التعليمي الذي جـاء بالمرتبـة الأولى حيث ان للمستوى

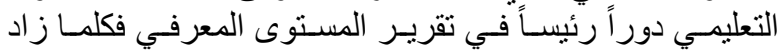

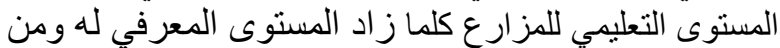

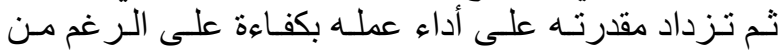
تو افر العو امل الأخرى التي تشجع على التى التغيير.

\section{3-الاستتتاجات والتوصيات}

-1-3 - 1-1 الاستتتاجات

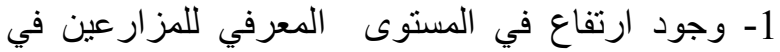
مجال الآفات الحشرية التي تصيب شجرة التئي الزيتون في

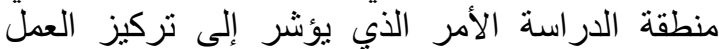

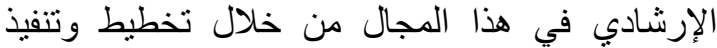

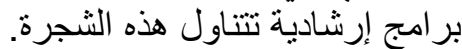

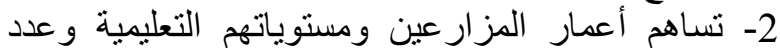

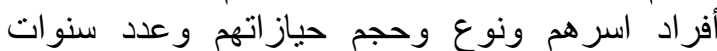

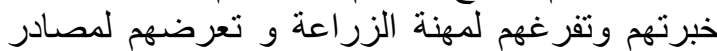

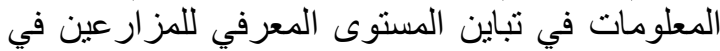

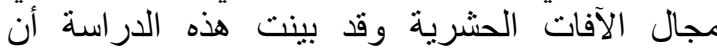

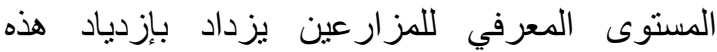

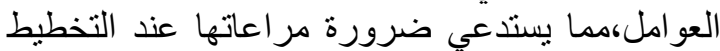

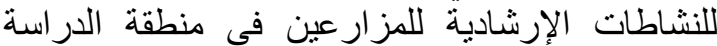
وذلك لطبيعة علاقتها بالمستويات المعرفية للمز ارعين. 2-3-3

1- تعزيز دور الإرشاد الزراعي في تعليم وتوعية

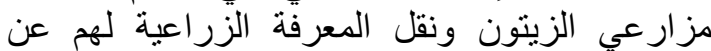

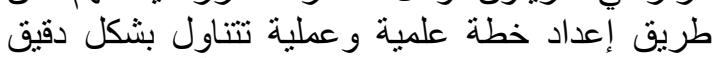

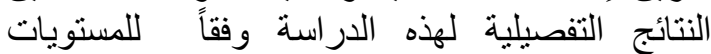
المعرفية للمزار عين في منطقة الدر اسة.

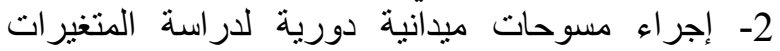

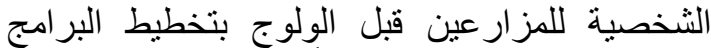

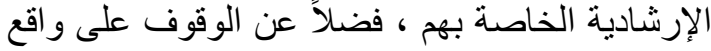

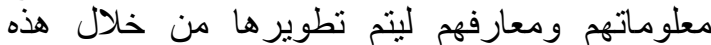

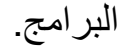
3- العمل على زيادة إشراك المزارعين في الدورات

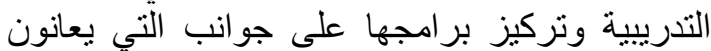
بضعف في مجالاتها.

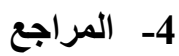

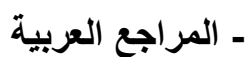

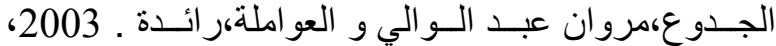

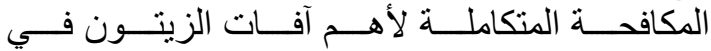

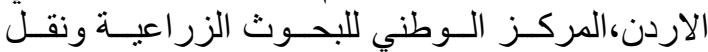

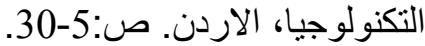

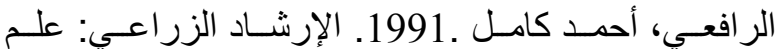

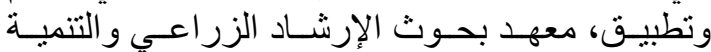

